\title{
Research Article: \\ Vitamin D3 Reduction in Individuals Exposed to Sulfur Mustard
}

\author{
Mohammad Mehdi Adibzadeh Seresgi ${ }^{1}$ (D), Susan Ardestani Kaboudanian² (D), Soghrat Faghihzadeh ${ }^{1}$ (D), Tooba Ghazanfari ${ }^{*}$ (D)
}

1. Department of Immunology, Immunoregulation Research Center, Shahed University, Tehran, Iran.

2. Department of Biochemistry, Insitute of Biochemistry and Biophysics, University of Tehran, Tehran, Iran.

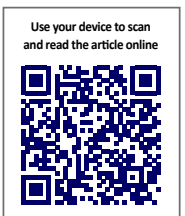

Citation Adibzadeh Seresgi MM, Ardestani Kaboudanian S, Faghihzadeh S, Ghazanfari T. Vitamin D3 Reduction in Individuals Exposed to Sulfur Mustard. Immunoregulation. 2019; 1(2):93-100. http://dx.doi.org/10.32598/Immunoregulation.1.2.87

http://dx.doi.org/10.32598/Immunoregulation.1.2.87

Funding: See Page 97

(c) Copyright: The Author(s)

\section{Article info:}

Received: 20 December 2017

Accepted: 28 April 2018

Available Online: 01 Jan 2019

Keywords:

Vitamin D deficiency,

Chronic inflammation,

Sulfur mustard, Calcium,

Phosphorus

\begin{abstract}
A B S T R A C T
Background: Inflammatory responses in individuals exposed to sulfur mustard occur in some organs such as lung, skin and eyes. These organs manifest overreaction in cellular and humoral immune responses. Over a long period, the immune responses often continues toward chronic inflammatory processes with some interventions. Obviously some elements have been deregulated. Therefore, this study evaluated Vitamin D3 levels as a modulatory agent that could first regulate inflammatory interactions, then switch to suppress inflammatory mechanisms. Several studies showed that Vitamin D3 plays an undeniable role in suppressing inflammatory responses. In addition, some studies showed that calcium and phosphorus could play some role in inflammatory responses, too. Also, levels of serum calcium and phosphorus are associated with serum Vitamin D3 level, because it promotes absorption and reabsorption of calcium and phosphorus in intestine and kidney.
\end{abstract}

Materials and Methods: Levels of vitamin D3, calcium and phosphorus were measured by ELISA and spectrophotometric method, respectively. 114 exposed individuals as case group and 79 unexposed as control group were evaluated.

Results: The results showed that the level of serum Vitamin D3 is low in individuals exposed to sulfur mustard $(\mathrm{P}<0.001)$. Also, there is a significant difference between exposed and control group in calcium level $(\mathrm{P}<0.001)$. However, serum phosphorus assay result showed no significant difference between two groups.

Conclusion: According to our findings, chronic inflammation has correlation with status of serum Vitamin D3 deficiency in individuals exposed to sulfur mustard.

\section{Introduction}

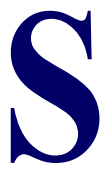

ulfur mustard as a war weapon was used during the past two decades [1]. It has been used more than other chemical gases in wars, thereby its effects has better known than other poisons [2]. Sulfur mustard gas was a mass killer in the final years of the First world war [3]. Also, this chemical agent was used by Iraqi army against Iranian soldiers during 1984-1988 imposed war [4]. Sulfur mustard is a strong alkylating agent with cytotoxic, carcinogenic and mutagenic properties. The

\section{* Corresponding Author:}

Tooba Ghazanfari, PhD

Address: Department of Immunology, Immunoregulation Research Center, Shahed University, Tehran, Iran.

Phone: +98 (21) 66418016

E-mail: tghazanfari@yahoo.com 
toxicity of this vesicatory agent has been identified since the past century $[5,6]$.

Sulfur mustard effects could occur as early complications (acute) and late complications (delayed) in a variety of organs such as lung, eyes, skin, nervous and digestive system, bone marrow, and immune system [7]. Delayed problems in lung, eyes and skin in exposed individuals indicate an interaction between the immune system and chronic inflammation [8-10]. Several reports show that functional disorder in humoral and cellular immunity would happen by contact with sulfur mustard [11-13]. In addition, inflammatory reactions could appear followed by reduction in level of serum Vitamin D3. Because of inflammation, people with Chronic Obstructive Pulmonary Disease (COPD) encounter difficulties in transportation of Vitamin D receptor to cytoplasm. Furthermore, Histone Deacetylase 2 (HDAC) with vitamin D3 regulate $\mathrm{NFKB}$, the transcription factor in expression of inflammatory cytokines, but expression of HDAC reduces followed by stress oxidative. Therefore, Vitamin D3 could not contribute in interaction of inflammatory mechanisms in order to modulate inflammatory responses and switching to equilibrium situation [14].

Vitamin D3 is an effective tool in suppressing inflammatory responses and also plays an essential role in keeping extracellular calcium and phosphorus concentration [15]. Moreover, its non-classical role in modulation of inflammatory state acts through inflammatory responses of immunity [16]. Vitamin D3 (active form of vitamin D) creates heterodimer with retinoic acid then binds to vitamin D receptor and stays on its promoter that is so-called Vitamin D binding element [17]. Consequently, inflammatory transcriptional factors expression such as NFKB, NFAT and so on were inhibited that decreases inflammatory cytokines and increases anti-inflammatory cytokines such as Interleukin (IL)12, IL23 and IL10 [18].

Generally, studies show that vitamin D deficiency exists in individuals with Chronic Obstructive Pulmonary Disease (COPD) [19-21]. Furthermore, calcium and phosphorus are other necessary elements in inflammation. Several studies showed that levels of serum and dietary calcium could reduce inflammation and also treatment with 1,25(OH)2D3 suppresses TNF- $\alpha$ (tumor necrosis factor-alpha) expression. Some studies report that phosphorus and hypophosphatemia is depleted in people with COPD and has correlation with respiratory failure $[22,23]$. In the present study, the level of serum calcium and phosphorus were measured.
On the other hand, individuals exposed to sulfur mustard are similar to people with COPD with respect to lung complications. Because of the importance of $\mathrm{Vi}$ tamin $\mathrm{D}$ in reducing inflammatory responses and few reports on investigating Vitamin D level in individuals exposed to sulfur mustard, we decided to evaluate the levels of serum Vitamin D3 in individuals exposed to sulfur mustard.

\section{Materials and Methods}

\section{Study population}

This was a case-control study with 193 participants, including 114 people exposed to sulfur mustard and 79 unexposed people as the control subjects. Al exposed and control subjects were male.

\section{Inclusion and exclusion criteria}

Inclusion criteria were having 30 to 60 years old and voluntarily participated in the study. The subjects had no observed diseases which intervened in our experiments. Furthermore, Exclusion criteria were those with using immunosuppressive drugs or Vitamin D supplement, having acute infectious diseases, missed laboratory samples, or developed Vitamin D disorder metabolism.

\section{Serum preparation}

Because of seasonal changes in serum Vitamin D, the blood was taken from all individuals in December which the procedure will be described briefly in the following sections. Initially, a sample of $5 \mathrm{~mL}$ of blood was taken and frozen to measure Vitamin D3 levels.

\section{Vitamin D3, Phosphorus and Calcium measurement}

Serum level of Vitamin D3 was measured with competitive ELISA method (bioactive diagnostic, $\mathrm{GmbH}$ ). At first, anti-vitamin D coated in each well and incubated with standard, control, and sample. Conjugated vitamin D-biotin was conjugated at room temperature for 90 min. After washing, TMB solution was dispensed and incubated at room temperature for $30 \mathrm{~min}$. Consequently, $\mathrm{H} 2 \mathrm{SO} 4$ as stop solution was used and the result was read at $450 \mathrm{~nm}$ wavelength.

Amount of $10 \mu \mathrm{L}$ of $25-\mathrm{OH}$ VD standards, controls and samples were dispensed into each well, as required. Then $100 \mu \mathrm{L}$ working solution of biotinylated $25(\mathrm{OH}) \mathrm{D}$ reagent was added into each well. Next, the plates were incubated at room temperature for 90 minutes. Afterwards, the contents of the wells were shacked out and $300 \mu \mathrm{L}$ of 
wash buffer was added into each well for 5 times. Then, $100 \mu \mathrm{L}$ of conjugated enzyme (streptavidin-HRP) was added into each well. After that, they were incubated at room temperature for 30 minutes and then $300 \mu \mathrm{L}$ of wash buffer was added into each well for 5 times. In this step, the multi-channel pipette was used and then 100 $\mu \mathrm{L}$ of TMB substrate was added into each well and incubated for 33 minutes at room temperature (in a dark place). Subsequently, $100 \mu \mathrm{L}$ of stop solution was added into each well to stop the enzymatic reaction and mixed plate contents for 20-30 s. The result was read at $450 \mathrm{~nm}$ wavelength. Level of serum phosphorus was measured by spectrophotometer based on routine methods.

\section{Cytokine assay}

In this study, IL-4 and IFN- $\gamma$ (Interferon gamma) cytokines were measured by Sandwich ELISA method (R\&D kit, Germany) which will be described briefly. Initially, $100 \mu \mathrm{L}$ of anti-mouse IL- 4 and IFN- $\gamma$ were dispensed into each well. After incubating for $12 \mathrm{~h}$ (overnight) and washing 5 times, various concentrations of standard and sample solutions were added to each well. After incubating for $1 \mathrm{~h}$ at $37^{\circ} \mathrm{C}$, the plates were washed five times and then conjugated antibody was added to each well. The plates were incubated at $37^{\circ} \mathrm{C}$ for $2 \mathrm{~h}$ again, then TMB substrate solution was added to each well. After washing, the reaction was stopped by $\mathrm{H} 2 \mathrm{SO} 4$ and optical density was read in 450 wavelength.

\section{Results}

Vitamin D3, calcium and phosphorus levels from 114 exposed and 79 unexposed individuals were analyzed in this study. The results demonstrated significant differences between two groups (Table 1).

\section{Vitamin D3}

The result showed a significant decrease in Vitamin D3 serum level in exposed group compared with that in the control group $(\mathrm{P}<0.001)$ (Figure 1).

\section{Calcium and phosphorus}

The results showed that level of serum calcium has increased remarkably in the exposed group in comparison to the control group $(\mathrm{P}<0.001)$. However, the results of serum phosphorus assay showed no significant differences between two groups $(\mathrm{P}=0.636)$ (Figure $2 \& 3)$.

\section{Vitamin D3, Calcium and Phosphorus correlation}

Results demonstrated no correlation between levels of serum vitamin D3 and calcium in the control and exposed groups $(\mathrm{P}=0.097)$. Also, there is no correlation

Table 1. Characteristics of study individuals exposed to sulfur mustard and control group

\begin{tabular}{ccc}
\hline Characteristics & Exposed & Control \\
\hline Number & 125 & 108 \\
\hline Age, $y$ & $30-60$ & $30-60$ \\
Sex & Male & Male \\
\hline $1,25(\mathrm{OH}) 2 \mathrm{D} 3(\mathrm{ng} / \mathrm{mL})$ & $24.003 \pm 18.324$ & $34.111 \pm 24.783$ \\
\hline Serum calcium $(\mathrm{mg} / \mathrm{dL})$ & $9.63 \pm 0.38$ & $9.27 \pm 0.40$ \\
\hline Serum phosphorus $(\mathrm{mg} / \mathrm{dL})$ & $3.59 \pm 0.62$ & $9.27 \pm 0.40$ \\
\hline
\end{tabular}

*All data were shown as No. or Mean \pm SD

Vitamin D3

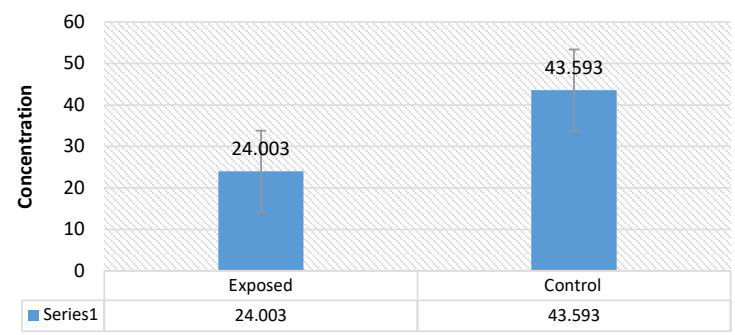

Vitamin D3

IMMUnoRegLLATION

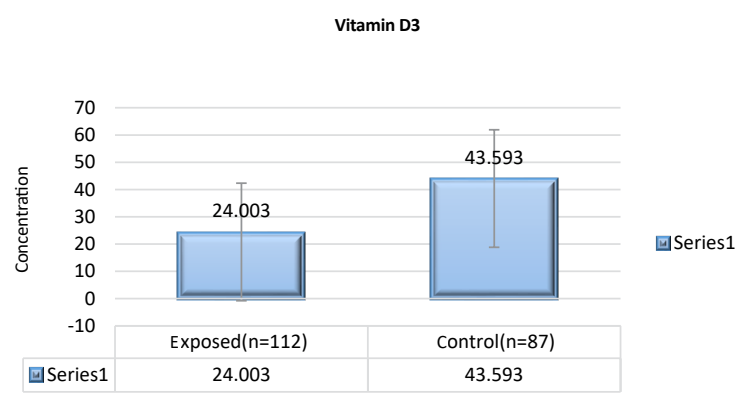

IMMUNOREGULATION

Figure 1. Vitamin D3 level measurement by ELISA method

There is a significant decrease in Vitamin D3 in exposed group as compared to the control group $(\mathrm{P}<0.001)$. 
Table 2. Results of vitamin D3, calcium and phosphorus correlation

\begin{tabular}{cccc}
\hline \multirow{2}{*}{ Factors } & \multicolumn{2}{c}{ VITD } \\
\cline { 3 - 4 } & & Exposed $(\mathbf{n}=\mathbf{1 1 2})$ & Control $(\mathbf{n}=\mathbf{8 7})$ \\
\hline Serum calcium & $\mathrm{r}^{*}$ & -0.039 & 0.180 \\
& $\mathrm{P}$ & 0.700 & 0.097 \\
Serum phosphorous & $\mathrm{r}^{*}$ & -0.094 & -0.377 \\
\hline * The Spearman rank correlation coefficient & $\mathrm{P}$ & 0.351 & $<0.001$ \\
\hline
\end{tabular}

Table 3. Results of vitamin D3, calcium and phosphorus correlation obtained by regression analysis

\begin{tabular}{|c|c|c|c|c|c|}
\hline \multicolumn{6}{|c|}{ Coefficients $^{a}$} \\
\hline \multirow{2}{*}{$\begin{array}{c}\text { Model } \\
\text { B }\end{array}$} & \multicolumn{2}{|c|}{ Unstandardized Coefficients } & \multirow{2}{*}{ Standardized Coefficients } & \multirow{2}{*}{$\mathrm{t}$} & \multirow{2}{*}{ Sig. } \\
\hline & Standard Error & Beta & & & \\
\hline (Constant) & 7.736 & 45.622 & & 0.170 & 0.866 \\
\hline Group & 19.949 & 4.210 & 0.430 & 4.739 & 0.000 \\
\hline Serum calcium & 2.676 & 4.121 & 0.049 & 0.649 & 0.517 \\
\hline Serum phosphorous & -9.622 & 2.580 & -0.247 & -3.729 & 0.000 \\
\hline Age & 0.217 & 0.230 & 0.074 & 0.943 & 0.347 \\
\hline
\end{tabular}

between phosphorus and vitamin D3 in exposed group $(\mathrm{P}=0.300)$. However, there is a significant and negative correlation between the control group and serum phosphorus level $(\mathrm{P}<0.001, \mathrm{r}=-0.377)$ (Table 2). The results of regression assay showed that vitamin D status has a significant correlation with group and level of serum phosphorus $(\mathrm{P}<0.0001)$ (Table 3$)$.

\section{Statistical analysis}

The obtained data were expressed as Mean \pm SD and analyzed in SPSS Vrsion 22. The Independent t-test, regression and Mann-Whitney test was used for comparison of the means of two groups. $\mathrm{P}$ values less than 0.05 were considered statistically significant.

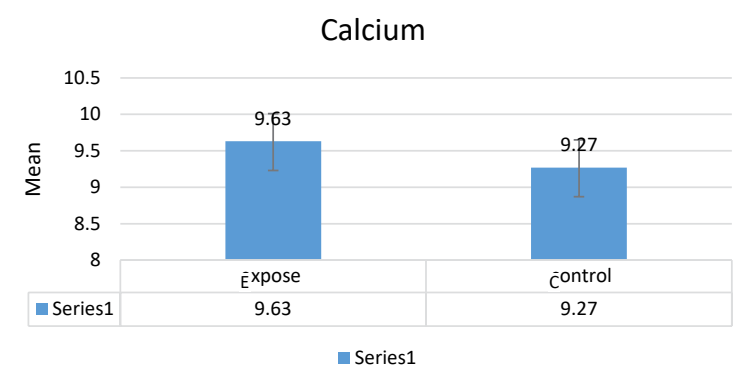

IMMUNoREGULATION

Figure 2. Serum level of calcium in exposed and control groups

\section{Discussion}

Vitamin D3 as an immunomodulatory agent enhances immune responses against infections and suppresses excessive inflammatory reactions. In addition, studies show that Vitamin D3 could suppress inflammatory cytokines and utilized as supplementary drug to treat inflammatory disorders such as autoimmune diseases. On the other hand, individuals who are exposed to sulfur mustard suffer from chronic pulmonary infections and their bronchus were obstructed and inflammatory cytokines were up-regulated. Furthermore, some studies indicate that people with COPD suffer from Vitamin D deficiency. Therefore, vitamin D3 has a critical role in suppressing inflammatory cytokines and establish homeostasis in

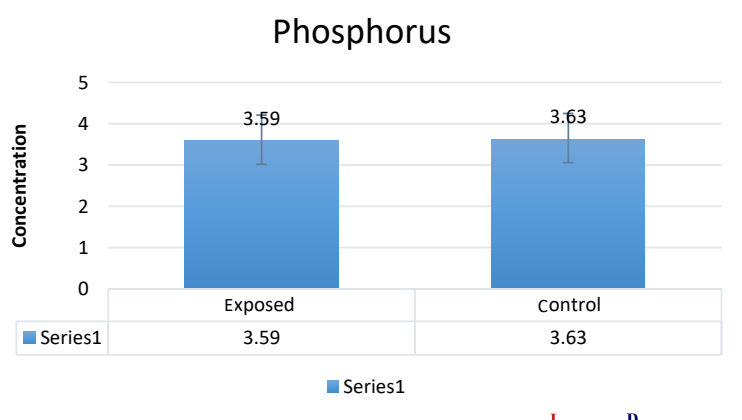

IMinunoRecuLATION

Figure 3. Serum level of phosphorus exposed and control groups 
body with prevention of inflammatory reactions. However, this equilibrium was perturbed when Vitamin D3 level is not sufficient. Also, calcium and phosphorus as functional components act within the network of Vitamin D3 performance [24-26].

In the present study, we showed a significant correlation between vitamin D3 status and lung chronic inflammation caused by sulfur mustard in exposed individuals to sulfur mustard as compared with the control group. Moreover, the level of serum calcium reveals a significant difference between the exposed group and control group. However, there are no significant differences between the exposed group and control group with regard to phosphorus level.

As we know, vitamin D has a classical role to absorb calcium and phosphorus in intestine [15, 27, 28]. Also, vitamin D3 operates as a regulator of immune system. Thus, vitamin D illustrates a new aspect of natural component of immunomodulation in this respect. As mentioned above, several studies revealed that individuals with COPD are deficient in vitamin D [20]. Also, Person et al. studied on the levels of vitamin D and lung function Forced Vital Capacity (FVC) and reported that vitamin $\mathrm{D}$ deficiency in individuals with COPD increases inflammatory cytokine, decreases FVC, and makes them susceptible to infection pulmonary [29]. In another study, Janssens et al. measured levels of serum Vitamin D, and reported a correlation between Vitamin D deficiency and COPD. Furthermore, they demonstrated a clear connection between levels of serum Vitamin D and lung function in individuals with COPD [21].

Barker et al. addressed the relationship between Vitamin D and pro-inflammatory cytokines. They concluded that Vitamin D deficiency coincide with increase in secretion of pro-inflammatory cytokines such as IFN- $\gamma$ and IL1 $\beta$ [30]. As we known, serum vitamin D is deficient in individuals exposed to sulfur mustard. Zhu et al. reported that serum and dietary calcium could reduce inflammation and also treatment with 1,25(OH)2D3 suppress $\mathrm{TNF} \alpha$ (tumor necrosis factor-alpha) expression synergically. Hyder et al. stated that phosphorus and hypophosphatemia were depleted in people with COPD and had correlation with respiratory failure $[22,23]$.

In the present study, calcium and Vitamin D level were low in exposed group as compared to control group. Therefore, inflammatory responses increases following vitamin $\mathrm{D}$ and calcium deficiency. On the other hand, phosphorus level has an important role in respiratory failure in individuals with COPD. Vitamin D deficiency could produce inflammation, meanwhile its molecular mechanism is not fully understood. Generally, there is an interaction between Vitamin D receptor with FoxO (Forkhead box) protein and its regulator, SIRT1, which inhibits inflammatory status in the lung $[31,32]$. This mechanism in individuals with inflammatory reactions in their lungs leads to lower activity of regulation of $H D A C 2$ via production of stress oxidative [14].

As a result, lower SIRT1 in inflamed lung followed by enhancement of NFKB activity could lead to more production of inflammatory cytokines. Also, Vitamin D function reduces followed by lack of Vitamin D receptor translocation into cytoplasm. Thereby, proinflammatory cytokines are expressed more. Taken together, in the present study individuals exposed to sulfur mustard showed insufficient levels of vitamin D3. Additionally, measurement of expression and activity of Vitamin D receptor are necessary to understand its mechanism of action.

As levels of serum Vitamin D3 reduces in individuals exposed to sulfur mustard, higher inflammatory responses in the lung could be seen in these people. Thus, Vitamin D3 deficiency is correlated to deregulation in Vitamin D3 immunomodulatory function to prevent excessive inflammatory responses in individuals exposed to sulfur mustard.

\section{Ethical Considerations}

\section{Compliance with ethical guidelines}

The study was approved by the Ministry of Health of Iran and the Board of Research Ethics of Veterans Medical and Engineering Research Center (Shahed. REC. 1392. 49). A written informed consent was obtained from all subjects in this study.

\section{Funding}

This study was performed and supported by Immunoregulation Research Center, Shahed University, Tehran.

\section{Conflict of interest}

The authors declare they have no conflict of interest.

\section{Acknowledgments}

The authors are grateful to Immunoregulation Research Center of Medical Faculty, Shahed University and especially appreciate Mrs. Sahar Salimi assistance. 


\section{References}

[1] Ghotbi L, Hassan Z. The immunostatus of natural killer cells in people exposed to sulfur mustard. International Immunopharmacology. 2002; 2(7):981-5. [DOI:10.1016/S15675769(02)00053-X]

[2] Ghabili K, Agutter PS, Ghanei M, Ansarin K, Panahi Y, Shoja MM. Sulfur mustard toxicity: History, chemistry, pharmacokinetics, and pharmacodynamics. Critical Reviews in Toxicology. 2011; 41(5):384-403. [DOI:10.3109/10408444.201 0.541224] [PMID]

[3] Le HQ, Knudsen SJ. Exposure to a First World War blistering agent. Emergency Medicine Journal. 2006; 23(4):296-9. [DOI:10.1136/emj.2005.032540] [PMID] [PMCID]

[4] Borak J, Sidell FR. Agents of chemical warfare: Sulfur mustard. Annals of Emergency Medicine. 1992; 21(3):303-8. [DOI:10.1016/S0196-0644(05)80892-3]

[5] Dacre JC, Goldman M. Toxicology and pharmacology of the chemical warfare agent sulfur mustard. Pharmacological Reviews. 1996; 48(2):289-326. [PMID]

[6] Ghanei M, Vosoghi AA. An epidemiologic study to screen for chronic myelocytic leukemia in war victims exposed to mustard gas. Environmental Health Perspectives. 2002 110(5):519-21. [DOI:10.1289/ehp.02110519] [PMID] [PMCID]

[7] Bobb AJ, Arfsten DP, Jederberg WW. N-acetyl-L-Cysteine as prophylaxis against sulfur mustard. Military Medicine. 2005; 170(1):52-6. [DOI:10.7205/MILMED.170.1.52] [PMID]

[8] Balali-Mood M, Hefazi M. Comparison of early and late toxic effects of sulfur mustard in Iranian veterans. Basic \& Clinical Pharmacology \& Toxicology. 2006; 99(4):273-82. [DOI:10.1111/j.1742-7843.2006.pto_429.x] [PMID]

[9] Javadi MA, Yazdani S, Sajjadi H, Jadidi K, Karimian F, Einollahi B, et al. Chronic and delayed-onset mustard gas keratitis: Report of 48 patients and review of literature. Ophthalmology. 2005; 112(4):617-25. [DOI:10.1016/j.ophtha.2004.09.027] [PMID]

[10] Khateri S, Ghanei M, Keshavarz S, Soroush M, Haines D. Incidence of lung, eye, and skin lesions as late complications in 34,000 Iranians with wartime exposure to mustard agent. Journal of Occupational and Environmental Medicine/ American College of Occupational and Environmental Medicine. 2003; 45(11):1136-43. [DOI:10.1097/01. jom.0000094993.20914.d1] [PMID]

[11] Ishida H, Ray R, Ray P. Sulfur mustard downregulates iNOS expression to inhibit wound healing in a human keratinocyte model. Journal of Dermatological Science. 2008; 49(3):207-16. [DOI:10.1016/j.jdermsci.2007.09.002] [PMID]

[12] Ghazanfari T, Kariminia A, Yaraee R, Faghihzadeh S, Ardestani SK, Ebtekar M, et al. Long term impact of sulfur mustard exposure on peripheral blood mononuclear subpopulations--Sardasht-Iran Cohort Study (SICS). International Immunopharmacology. 2013; 17(3):931-5. [DOI:10.1016/j. intimp.2012.12.023] [PMID]

[13] Moin A, Khamesipour A, Hassan ZM, Ebtekar M, Davoudi SM, Vaez-Mahdavi MR, et al. Pro-inflammatory cytokines among individuals with skin findings long-term after sulfur mustard exposure: Sardasht-Iran Cohort Study. International Immunopharmacology. 2013; 17(3):986-90. [DOI:10.1016/j.intimp.2012.12.022] [PMID]
[14] Barnes PJ. Role of $H D A C 2$ in the pathophysiology of COPD. Annual Review of Physiology. 2009; 71:451-64. [DOI:10.1146/annurev.physiol.010908.163257] [PMID]

[15] Ginanjar E, Sumariyono, Setiati S, Setiyohadi B. Vitamin D and autoimmune disease. Acta Medica Indonesiana. 2007; 39(3):133-41. [PMID]

[16] Aranow C. Vitamin D and the immune system. Journal of Investigative Medicine. 2011; 59(6):881-6. [DOI:10.2310/ JIM.0b013e31821b8755] [PMID] [PMCID]

[17] Trochoutsou AI, Kloukina V, Samitas K, Xanthou G. Vitamin-D in the Immune System: Genomic and non-genomic actions. Mini Reviews in Medicinal Chemistry. 2015; 15(11):95363. [DOI:10.2174/1389557515666150519110830] [PMID]

[18] Gynther P, Toropainen S, Matilainen JM, Seuter S, Carlberg C, Vaisanen S. Mechanism of 1alpha,25-dihydroxyvitamin $\mathrm{D}(3)$-dependent repression of interleukin-12B. Biochimica et biophysica Acta. 2011; 1813(5):810-8. [DOI:10.1016/j.bbamcr.2011.01.037] [PMID]

[19] Ferrari M, Schenk K, Papadopoulou C, Ferrari P, Dalle Carbonare L, Bertoldo F. Serum 25-hydroxy vitamin D and exercise capacity in COPD. Thorax. 2011; 66(6):544-5. [DOI:10.1136/thx.2010.152785] [PMID]

[20] Finklea JD, Grossmann RE, Tangpricha V. Vitamin D and chronic lung disease: A review of molecular mechanisms and clinical studies. Advances in Nutrition. 2011; 2(3):24453. [DOI:10.3945/an.111.000398] [PMID] [PMCID]

[21] Janssens W, Bouillon R, Claes B, Carremans C, Lehouck A, Buysschaert I, et al. Vitamin D deficiency is highly prevalent in COPD and correlates with variants in the vitamin D-binding gene. Thorax. 2010; 65(3):215-20. [DOI:10.1136/ thx.2009.120659] [PMID]

[22] Fiaccadori E, Coffrini E, Fracchia C, Rampulla C, Montagna T, Borghetti A. HYpophosphatemia and phosphorus depletion in respiratory and peripheral muscles of patients with respiratory failure due to copd. Chest. 1994; 105(5):1392-8. [DOI:10.1378/chest.105.5.1392] [PMID]

[23] Zhu Y, Mahon BD, Froicu M, Cantorna MT. Calcium and 1 alpha,25-dihydroxyvitamin D3 target the TNF-alpha pathway to suppress experimental inflammatory bowel disease. European Journal of Immunology. 2005; 35(1):217-24. [DOI:10.1002/eji.200425491] [PMID]

[24] Demay MB. Mechanism of vitamin D receptor action. Annals of the New York Academy of Sciences. 2006; 1068(1):20413. [DOI:10.1196/annals.1346.026] [PMID]

[25] Omdahl JL, Morris HA, May BK. Hydroxylase enzymes of the vitamin D pathway: Expression, function, and regulation. Annual Review of Nutrition. 2002; 22(1):139-66. [DOI:10.1146/annurev.nutr.22.120501.150216] [PMID]

[26] Subramanian K, Bergman P, Henriques-Normark B. Vitamin D promotes pneumococcal killing and modulates inflammatory responses in primary human neutrophils. Journal of Innate Immunity. 2017; 9(4):375-86. [DOI:10.1159/000455969] [PMID]

[27] Davis CD, Milner JA. Nutrigenomics, vitamin D and cancer prevention. Journal of Nutrigenetics and Nutrigenomics. 2011; 4(1):1-11. [DOI:10.1159/000324175] [PMID] [PMCID] 
[28] Sheng L, Callen DF, Turner AG. Vitamin D3 signaling and breast cancer: Insights from transgenic mouse models. The Journal of Steroid Biochemistry and Molecular Biology. 2018; 178:348-53. [DOI:10.1016/j.jsbmb.2018.02.006] [PMID]

[29] Persson LJ, Aanerud M, Hiemstra PS, Hardie JA, Bakke PS, Eagan TM. Chronic obstructive pulmonary disease is associated with low levels of vitamin D. PloS One. 2012; 7(6):e38934. [DOI:10.1371/journal.pone.0038934] [PMID] [PMCID]

[30] Barker T, Martins TB, Hill HR, Kjeldsberg CR, Dixon BM, Schneider ED, et al. Circulating pro-inflammatory cytokines are elevated and peak power output correlates with 25-hydroxyvitamin D in vitamin D insufficient adults. European Journal of Applied Physiology. 2013; 113(6):1523-34. [DOI:10.1007/s00421-012-2582-7] [PMID]

[31] An BS, Tavera-Mendoza LE, Dimitrov V, Wang X, Calderon MR, Wang HJ, et al. Stimulation of Sirt1-regulated FoxO protein function by the ligand-bound vitamin $\mathrm{D}$ receptor. Molecular and Cellular Biology. 2010; 30(20):4890-900. [DOI:10.1128/MCB.00180-10] [PMID] [PMCID]

[32] Rajendrasozhan S, Yang SR, Kinnula VL, Rahman I. SIRT1, an antiinflammatory and antiaging protein, is decreased in lungs of patients with chronic obstructive pulmonary disease. American Journal of Respiratory and Critical Care Medicine. 2008; 177(8):861-70. [DOI:10.1164/rccm.2007081269OC] [PMID] [PMCID] 
